\title{
Desemprego: discurso e silenciamento - um estudo com clientes de um serviço de aconselhamento psicológico ${ }^{1}$
}

\author{
Carolina Passos Terra, Joari Aparecido Soares de Carvalho, \\ José Eduardo Assunção Azevedo, Luciana de Albuquerque Venezian e \\ Sérgio Bacchi Machado \\ Instituto de Psicologia da Universidade de São Paulo
}

\begin{abstract}
O objetivo desta pesquisa foi discutir a relação entre o fenômeno do desemprego e o sofrimento psíquico na atualidade. A pesquisa teve caráter qualitativo e se baseou na análise de entrevistas semidirigidas. Foram entrevistados clientes do Serviço de Aconselhamento Psicológico (SAP) do Instituto de Psicologia da USP. A quantidade de pessoas interessadas em falar sobre a questão e a diversidade de suas origens sociais surpreenderam os pesquisadores. No processo de análise das entrevistas, observamos uma recorrente queixa de impossibilidade de se falar sobre a experiência pessoal do desemprego. Sobre essas queixas, analisamos dois aspectos em tensão: a heterogeneidade das significações da experiência do desemprego e a ideologia homogeneizante sobre a expressão do emprego/desemprego. Construímos três hipóteses para problematizar esses aspectos e para ampliar as possibilidades de exercício de uma psicologia que compreenda a singularidade da experiência psicossocial no âmbito da clínica e da psicologia social do trabalho.
\end{abstract}

Palavras-chave: Desemprego, Psicologia social, Psicologia do trabalho, Psicologia clínica, Aconselhamento psicológico, Sofrimento psíquico.

Unemployment: speech and silencing - a research with clients of a counseling service

The aim of this research was to discuss the relation between unemployment and psychic suffering nowadays. This research has qualitative approach and was based on semi-directive interviews. The interviewed people were clients from a Counseling Service (Psychology Institute, USP). The number of interested people to talk about unemployment and their several social backgrounds were both outstanding surprises. In the analyze process of interview, different expressed claims about of the social impossibility to talk about personal experience of unemployment were dethetabled. From these expressions, two aspects in tension were analyzed: the different meanings of unemployment experience, and the effects of a homogeneous ideology over the employment questions. This research shows three hypotheses to problematizing these aspects and to broadening the exercise of a psychology that leads to understand the specific psychosocial experience at fields of the clinic and of the social sychology of work.

Keywords: Unemployment, Social psychology, Work psychology, Clinical psychology, Counseling, Psychic suffering.

Até então, pelo menos ele se calava, entregue a esse desespero em que uma condição, mesmo quando julgada injusta, é aceita. Calar-se é deixar que acreditem que não se julga nem que se deseja nada, e em certos casos é, na realidade, nada desejar.

Albert Camus

\section{Apresentação}

A recorrência da temática do desemprego nos atendimentos de um serviço de aconselhamento psicológico motivou a realização de pesquisas que pudessem trazer

1 Pesquisa desenvolvida como estágio sob a supervisão da professora Leny Sato. A proposta inicial do projeto incluía a professora Maria Luísa Sandoval Schmidt. Além dos autores, a equipe de estagiários contava com Marcos Gatti e Mariana Ali Mies. Agradecemos às professoras, aos colegas da equipe e também: à Tânia, à Odete, ao Flávio e ao Samir. 
novas perspectivas sobre o assunto. Baseando-nos numa pesquisa desenvolvida por Menezes Júnior et al. (1999) e na nossa própria experiência como estagiários nesse serviço, constatamos que no âmbito dos atendimentos psicológicos a questão do desemprego aparecia como fenômeno que não participava da conformação dos objetos próprios de atenção na prática clínica em psicologia, apresentando-se como fenômeno externo à esfera psíquica. Essas constatações e o processo de familiarização com o tema mobilizaram-nos na direção de refletir sobre a seguinte questão: como o desemprego se comunica com o sofrimento psíquico?

A realização deste trabalho compreendeu três momentos diferentes: num primeiro, mergulhamos no tema e amadurecemos a questão da pesquisa, por meio de leituras de textos e discussões semanais; num segundo, partimos para a pesquisa de campo, na qual entrevistamos clientes do Serviço de Atendimento Psicológico do Instituto de Psicologia da Universidade de São Paulo (SAP) ${ }^{2}$ e, num terceiro momento, analisamos os dados.

\section{O mergulho}

O primeiro momento da pesquisa foi constituído por leituras, discussões e reflexões. Isso nos permitiu situar a superfície do fenômeno sobre o qual nos debruçávamos e, a cada nova leitura, discussão e reflexão, avançar nesse mergulho.

O ponto de partida foi constituído pelas considerações de Jahoda (1987), no campo da psicologia social, acerca da definição e dos usos comuns das idéias de trabalho e de emprego na sociedade. Reconhecemos aqui uma diferenciação conceitual entre as idéias. $\mathrm{O}$ trabalho refere-se a um conceito quase generalizado como uma ação com vistas à satisfação, numa vertente de pensamento, ou como conservação econômica, noutra vertente. $\mathrm{O}$ emprego refere-se a uma modalidade de trabalho regulada por uma relação contratual formal, que define direitos e deveres de empregados e de empregadores. Comparativamente com outras modalidades de trabalho, o empregado goza de maior prestígio social por causa de suas garantias legais. Há também uma idéia complexa a respeito de modalidades de trabalho organizadas por outras lógicas, como o trabalho informal e o autônomo, que vêm ocupando maior espaço no mundo do trabalho em face da crise da sociedade industrializada. Esses conceitos e idéias, consciente ou inconscientemente, vem sendo fundamentados por distintos valores e princípios ideológicos.

Essa complexidade dos conceitos alertou-nos para a necessidade de compreender algumas implicações das definições, particularmente nas estatísticas e nos índices de desemprego no Brasil. Recorremos aos dados de dois tradicionais índices de desemprego, a $\mathrm{PME}^{3}$ e a $\mathrm{PED}^{4}$, e notamos que havia uma diferença relevante nos conceitos de desemprego, que se desdobravam em índices muito diferentes, os quais geralmente são divulgados para a opinião pública e sustentam várias estratégias de políticas públicas articuladas a interesses diversos ${ }^{5}$.

2 O SAP é um serviço de atendimento feito em forma de plantão psicológico. Foi criado em 1968 no Instituto de Psicologia da Universidade de São Paulo e é oferecido ao público em geral desde então. Ver: Rosenberg (1987) e Eisenlohr (1999).

3 Pesquisa Mensal de Emprego do Instituto Brasileiro de Geografia e Estatística (IBGE) formulada com base na Taxa de Desemprego Aberto da População Economicamente Ativa (PEA), que é uma relação entre "o número de pessoas desocupadas (procurando trabalho) e o número de pessoas economicamente ativas num determinado período de referência” (IBGE, 2002).

4 Pesquisa de Emprego e Desemprego do convênio da Fundação Sistema Estadual de Análise de Dados (SEADE) e do Departamento Intersindical de Estatística e Estudos Sócio-Econômicos (DIEESE) formulada com base na soma das taxas de desemprego aberto, oculto pelo trabalho precário e oculto pelo desalento na População em Idade Ativa, PIA (DIEESE, $2002 b)$.

5 A respeito das implicações desses conceitos sobre os índices de desemprego no Brasil, conferir o texto A posição do DIEESE sobre a controvérsia das taxas de desemprego no Brasil (DIEESE, 2002a). 
Adiante, com a contribuição de Mattoso (1994), alcançamos as explicações macrosociais para o fenômeno do desemprego. O problema objetivo é situado numa perspectiva histórica, focalizando a transição entre as macropolíticas do Estado de Bem Estar Social (Welfare State) e da reforma conservadora ou neoliberal. A estrutura de garantias de direitos sociais construída após a Segunda Guerra Mundial, principalmente na Europa e nos EUA, estaria sendo solapada por uma tendência de perda das garantias sociais, individuais e coletivas, nas últimas três décadas recentes, em geral, nos países que aderiram à onda econômica do mercado livre globalizado. Um desdobramento dessas mudanças seria o aumento brutal dos índices de desemprego, em função da alta competitividade internacional e do abandono do caráter sócio-inclusivo da economia.

Continuando o mergulho, alcançamos a dimensão psicossocial por meio das idéias de Seligmann-Silva (1999), que situa o problema do desemprego no campo da saúde do trabalhador. Vimos, então, algumas implicações atuais da reestruturação produtiva do trabalho sobre a saúde do trabalhador, sobretudo os seus resultados psicopatológicos decorrentes da deterioração proporcionada pelo desemprego à sociabilidade.

Tivemos também contato com as idéias da romancista e ensaísta Viviane Forrester (1997), quem aponta enfaticamente a impossibilidade da exigência de trabalho e de emprego, considerando o último um disfarce perverso do primeiro, uma vez que esse trabalho deixou de existir e de ser amplamente oferecido no mundo atual. Um desdobramento dessa realidade para a subjetividade seria uma identidade social fraturada, já que sua constituição historicamente tem dependido da experiência do trabalho.

Nosso mergulho foi concluído com as considerações de Castel (2001), com base no campo da sociologia do trabalho. Ele explora a questão por meio da idéia de que, em uma sociedade salarial, os indivíduos se situariam em zonas de maior ou menor vulnerabilidade ou segurança, considerando o grau de inserção/isolamento social e o de integração/exclusão no emprego. Assim, com a crise atual do trabalho, haveria uma significativa vulnerabilização das condições sociais dos indivíduos.

\section{De volta à tona}

Com o mergulho, pudemos perceber que o fenômeno do desemprego aparecia como tema configurado para diversas áreas de conhecimento, tais como a política, a economia, a sociologia, a história. Além disso, percebemos como esse fenômeno, ainda que de maneira restrita, tem interessado também à psicologia.

A psicologia social tem abordado o assunto de forma veemente. Além disso, notamos que cada vez mais se problematiza a postura predominante na psicologia clínica, que, por vezes, tem se colocado à margem das questões sociais, centrando seu olhar no indivíduo isolado da cultura ou restringindo-se a apenas alguns de seus aspectos ${ }^{6}$.

Se, até recentemente, o desemprego tinha pouco espaço no debate da psicologia clínica, agora, a manifestação cada vez mais intensa e freqüente do fenômeno nos atendimentos clínicos sugere a urgente e necessária revisão da atuação da psicologia, em particular de seus dispositivos teórico-metodológicos. A presente pesquisa pretende contribuir com a comunicação entre psicologia clínica e psicologia social do trabalho, buscando trazer à luz a repercussão da questão do desemprego na dinâmica das relações sociais e intersubjetivas, sobretudo atualmente. 
Para tanto, procuramos questionar relações entre a subjetividade e o desemprego que atualmente têm aparecido com grande freqüência nos meios de comunicação e no discurso da população sob diferentes formas, como a idéia de que o desemprego gera necessariamente sofrimento psíquico, especificamente a depressão.

\section{O encontro}

Melhor situados quanto ao fenômeno do desemprego, pudemos definir a condução do trabalho de campo. Desde a formação do grupo de pesquisadores no primeiro semestre de 2002, a pesquisa passou por reformulações de objetivos e pelo desafio de constituir uma metodologia apropriada.

Discutimos as possíveis implicações de solicitar que as pessoas falassem, em uma entrevista semidirigida, sobre seus sofrimentos. Cogitamos se que esses encontros poderiam provocar uma indiscriminação com o próprio atendimento prestado pelo SAP, tanto pelos entrevistados quanto pelos entrevistadores, uma vez que alguns entrevistadores eram plantonistas e os entrevistados seriam convidados entre os clientes do plantão.

Para Hermann (1997) e Luna (2001), pesquisa e atendimento psicológico podem caminhar juntos considerando as respectivas implicações da relação. Mas, mesmo assim, nossa opção metodológica foi a de nos restringir à realização de entrevistas sem pretensão psicoterapêutica. Esse recorte metodológico fundamenta a compreensão do procedimento adotado na condução das entrevistas e das análises. Procuramos, assim, garantir que o terapeuta e o entrevistador dos clientes do serviço não fossem a mesma pessoa.

A partir do momento em que a diferenciação metodológica tornou-se efetiva, surgiunos outro problema: Como a deixar clara para nossos entrevistados? Como os convidar a participar de uma pesquisa que não interferisse diretamente em seus respectivos atendimentos? O simples fato de os entrevistadores e os psicoterapeutas serem pessoas diferentes não garantia essa diferenciação. Concluímos que o contato inicial deveria ser esclarecedor em relação ao objetivo da pesquisa e o menos invasivo possível.

Optamos pela realização de entrevistas semidirigidas a fim de possibilitar depoimentos pessoais, ricos em narrativas, de modo a expressar a comunicação do entrevistado com sua experiência, convidando-o a um trabalho de memória que envolvesse construção ativa de sentidos (Bosi, 1998). Para isso, formulamos questões simples, que provocaram a reflexão encarnada em narrativas durante as entrevistas; na medida da necessidade de restringir o campo da entrevista e orientar a produção narrativa, sem a intenção de encerrar os objetivos da entrevista por eles, foram propostos temas referentes gerais da pesquisa (Gonçalves Filho, s. d.), compreendidos por: família, história de vida e de trabalho, a questão do desemprego atual e o papel da psicologia e de outras instituições no trato com a questão. ${ }^{7}$

Nos dias de plantão psicológico do $\mathrm{SAP}^{8}$, deixamos disponíveis fichas aos clientes na secretaria do serviço, no ato da inscrição, contendo o seguinte texto:

Está interessado em participar de uma pesquisa na USP?

\footnotetext{
$7 \mathrm{Nem}$ todos os referentes estão presentes na conclusão deste trabalho, pois houve uma escolha no foco de desenvolvimento da análise que priorizou aspectos destacados das várias entrevistas na coleta de depoimentos.

8 O plantão de aconselhamento psicológico do SAP, na ocasião, era oferecido às quartas-feiras, nos períodos da manhã e da tarde.
} 
Queremos saber como o desemprego afeta a vida das pessoas. Se você tem alguma coisa a dizer sobre esse assunto e quer dividir conosco, anote o seu nome e telefone nesta ficha e devolva no guichê onde esta lhe foi entregue, sem compromisso. Em breve entraremos em contato.

Estudantes do Centro de Psicologia Aplicada ao Trabalho e do Serviço de Aconselhamento Psicológico.

Não tivemos como critério inicial restringir nossos entrevistados a pessoas em situação de desemprego. Assim, abrimos a possibilidade de contato com aqueles que de alguma forma se sentiam afetados pelo desemprego e quisessem e pudessem se manifestar.

Nossa primeira surpresa se deu justamente quando obtivemos o resultado da distribuição das fichas em três períodos de plantão do SAP: das 50 distribuídas, 11 homens e 27 mulheres ofereceram-se para participar da pesquisa (o que corresponde a aproximadamente três quartos do total distribuído) deixando telefone para contato. $\mathrm{O}$ número de pessoas dispostas a participar superou nossas expectativas. Inferimos que há demanda das pessoas para falar sobre o desemprego, de suas experiências pessoais e concretas a respeito do fenômeno, ou seja, falar sobre como o desemprego atravessa suas vidas.

Com as fichas preenchidas em mãos, fizemos contatos telefônicos com os interessados. Esclarecemos o objetivo da pesquisa e a dissociamos do possível atendimento psicológico oferecido à pessoa. Esclarecemos ainda que, caso houvesse permissão, gravaríamos a entrevista para posterior transcrição e análise, visando a publicação de artigo sobre o assunto9. Quando houve concordância da pessoa com essas condições, telefonamos uma segunda vez a fim de marcar data e local ${ }^{10}$ para a realização das entrevistas.

Norteados apenas pelos temas referentes, realizamos as entrevistas sem um roteiro rígido preestabelecido. Nossa preocupação era possibilitar que a pessoa configurasse o campo da entrevista (Bleger, 1985) a fim de termos acesso ao maior número possível de informações, sempre tendo como norte nosso objeto de investigação. Evidentemente, não nos excluímos desse campo, pelo contrário, a pretensa neutralidade do entrevistador impossibilitaria a configuração do campo por parte do entrevistado. Dessa forma, não apenas o discurso transcrito foi material de análise, mas a entrevista como um todo.

As entrevistas ganharam contornos imprevistos, variando imensamente em forma e conteúdo. Dar conta da diversidade dos assuntos tornou-se um desafio. Para tanto, aproximamo-nos do pensamento de Hannah Arendt (1997), quando ela articula política e identidade social, uma vez que sem a política, compreendida como campo de confrontação de opiniões em presença dos homens, desconheceríamos a:

...recompensadora alegria que surge de estar na companhia de nossos semelhantes, de agir conjuntamente e aparecer em público; de nos inserirmos no mundo pela palavra e pelas ações, adquirindo e sustentando assim nossa identidade pessoal e iniciando algo inteiramente novo (p. 325).

\section{O Olhar}

A partir das transcrições das entrevistas, demos início a um ciclo de discussões e reflexões. Por exemplo, revimos uma espécie de "perfil esperado" de pessoas dispostas a

9 Posteriormente, foram atribuídos nomes fictícios aos entrevistados para garantir o sigilo de suas identidades.

10 As entrevistas foram realizadas no próprio Centro de Antendimento Psicológico do Instituto de Psicologia da USP. 
relatar como o desemprego se comunica com o sofrimento psíquico, que não se confirmou, uma vez que pessoas situadas em distintos segmentos do espaço social se dispuseram a ceder seus depoimentos. Tivemos, entre os entrevistados, pessoas empregadas e desempregadas, exempresário, ex-gerente, estudantes de curso universitário, ex-operária, profissional de recursos humanos, dentre outros. Podemos dizer que poucas das entrevistas corresponderam a um perfil esperado de alguém de meia-idade, com baixo nível escolar e que perdera ou que tivera dificuldade de se manter em um posto de trabalho ${ }^{11}$. Alguns de nós terminamos as entrevistas com a sensação de que algo não havia "dado certo". Comentários como: "Acho que minha entrevista não vai servir...”; e questões como: "Por que essa pessoa quis dar entrevista?", expressavam uma sensação de desconforto no grupo de pesquisa.

Se levássemos em conta os índices de desemprego do IBGE (2002) e do DIEESE (2002b) constataríamos que esse é um fenômeno generalizado e, portanto, não deveria causar-nos espanto a variedade de pessoas dispostas a serem entrevistadas. Porém, nos surpreendemos. E por que isso? Não imaginávamos haver tanta demanda em se falar sobre o desemprego em uma população tão variada como a que se apresentou. Surpreendeu-nos, também, aparecer essa demanda entre os clientes do SAP, o que corrobora as idéias de Schmidt (2004) a respeito de uma visão estratigráfica corrente na psicologia.

Diante de tal diversidade, a compreensão sobre as formas por meio das quais o desemprego se comunica com o sofrimento só pôde dar-se ao considerarmos os valores, as expectativas, o projeto de vida e os sentimentos de cada um em seu contexto de vida: sua posição relativa no espaço social (Bourdieu, 1996). Por esse motivo, optamos por apresentar os dados das entrevistas caso a caso, e não através de uma leitura temática que incorporasse em cada tema os achados dos diversos casos.

Apresentaremos cinco análises de entrevistas de um conjunto de treze realizadas. Cada entrevista possibilitou-nos entrar em contato com uma vivência peculiar do desemprego. Diante de um material de pesquisa tão rico e extenso, deparamo-nos com a necessidade de nos restringir aos temas predominantes em cada entrevista. Escolhemos das entrevistas, as cinco que nos "impactaram" por sua marca singular na relação com desemprego, permitindo-nos dirigir a pesquisa para a heterogeneidade da questão, embora tenha sido o conjunto das entrevistas que nos direcionou para a formulação de hipóteses no presente trabalho.

\section{Luísa: o trabalho na vida e a vida sem trabalho}

Luísa tem 32 anos, é casada, mãe de um filho de cinco anos e está grávida. Ela considera interessante uma pesquisa sobre desemprego, situação que está vivendo, e, por isso, concedeu a entrevista. A sua própria procura pelo atendimento do SAP deveu-se à busca de apoio para lidar com o que ela chama de "depressão" e de "desânimo" provocados pelo seu atual desemprego e pela falta de esperança em conseguir outro emprego satisfatório. "Depois de você tanto procurar e não achar nada, você acaba aceitando que você não consegue nada mesmo, então, pra que eu vou tentar?".

Dos 13 aos 32 anos ela passou por treze empregos, em áreas e funções diferentes. Nessa trajetória, várias decisões em sua vida foram guiadas pela possibilidade de manter o emprego ou de mudar para outro: "...como eu morava sozinha, né, eu tinha que conseguir emprego rápido porque pagava aluguel, tudo"; “...eu também saí de lá [empresa multinacional de autopeças], né, porque eu tinha entrado na faculdade, tava morando em São Paulo, tinha casado e ficava meio difícil trabalhar em Cotia e aí... eu acabei saindo de lá". 
Depois de ter o primeiro filho, tornou-se cada vez mais difícil encontrar um novo emprego, ainda mais um que lhe fosse agradável. Essa situação, segundo ela, é fruto de discriminação contra as mulheres no trabalho, sobretudo contra as mulheres que são mães, o que se manifesta tanto por preterimentos em seleções, quanto no próprio trabalho desvalorizado: "...a outra moça que teve filho também, logo depois que ela teve filho, ela voltou, mas... diminuíram as responsabilidades dela. Ela ficou numa posição que teve que acabar saindo". Luísa se reconhece nessa condição bastante incômoda e fragilizada de vítima de preconceitos.

Com base em experiências pessoais, Luísa critica veementemente também outros abusos contra os candidatos a empregos e os empregados. Ela destaca, por exemplo, baseada nas suas experiências: consultorias de recolocação falaciosas, que oferecem e garantem novos empregos e não cumprem o prometido; seleções capciosas que, além de demasiadamente extensas, com enormes questionários psicológicos, às vezes invadem a vida privada dos candidatos, questionando-os constrangedoramente sobre a vida sexual; exigências exorbitantes e descabidas de formação, que tendem a priorizar o diploma, mesmo "forjado", em detrimento da experiência de trabalho; empregos em condições precárias, com extensa jornada, sem benefícios, direitos nem perspectiva de melhoria profissional. Segundo ela, "falta consideração" com os desempregados por parte de quem oferece os empregos e, mais grave, "tem gente ganhando dinheiro em cima da desgraça dos outros, né".

Como grande parcela da população, ela não só tem o emprego como forma de subsistência, o que representa um lugar econômico na cadeia produtiva, mas também como forma de conviver e se relacionar com outras pessoas, o que representaria um espaço de sociabilidade. E, atualmente, diante da desestabilização da certeza do emprego, ela se vê excluída e expropriada da vida em suas várias esferas, não só econômica, mas também psicossocial.

Ela descreve várias das relações sociais que o desemprego afetou drasticamente, referindo-se a um sentimento de profundo "isolamento". Na família, Luísa e seu marido compunham a renda juntos e com o seu desemprego há uma grande perda para todos: seus planos de estudo foram adiados ou mesmo abandonados; encontros com os parentes são evitados porque o custo, mesmo que em cifras baixas, interfere no balanço econômico da família. Na comunidade, sair com amigos tornou-se inviável, já que não pode pagar as despesas, por exemplo, dividir o custo de uma "pizza". Essas convivências tornaram-se constrangedoras e motivo de vergonha, o que é agravado porque suas relações pessoais mais intensas eram justamente com os companheiros de trabalho. Cabe pensar se os sentimentos de "depressão" e de "desespero", relatados por ela, seriam implicações evidentes (sintomáticas) da própria dissolução de vínculos sociais constituintes de sua identidade.

A gente [família] não tem um convívio social com as pessoas do bairro. E, no fim, você acaba sentindo falta desse contato social que você tem no trabalho. Que o trabalho acaba virando uma espécie assim de família, sei lá, né.

E quando você tá desempregado, você perde isso [convívio social], né. Você... eu, por exemplo, às vezes eu não gosto de ligar pras pessoas que estão no trabalho, que são meus amigos, você fala: "ah, mas vou ligar, tá ocupada, tô fazendo isso, e eu tô aqui sem fazer nada", né. Você acaba perdendo, né, o contato com as pessoas. E pelo fato de você também não tá bem, eu acho que afeta também um pouco o orgulho das pessoas, né. Fala assim: "É, eu também não vou ter nada pra contar, né".

As perspectivas de trabalho e de vida representam, para ela, um dilema entre o passado, aparentemente seguro e confiável, e um presente que se mostra incerto, caótico e opressor. Mesmo considerando realizar algum trabalho informal para obter renda, ela se interessa ainda em recuperar um emprego bom e bem pago. O seu parâmetro de referência 
para uma possível nova ocupação é, mesmo reconhecidamente raro, o emprego assalariado. $\mathrm{O}$ trabalho informal adquire um sentido indesejado, como se fosse uma alternativa sem escolha, paradoxalmente, em uma condição de quase absoluta submissão a empregos precários. Assim, ela sustenta a fantasia de que reencontrar um bom emprego pode significar o reencontro de si mesma.

...você acaba falando: "Ah, agora eu vou qualquer coisa". E esse qualquer coisa é horrível porque quando você vai trabalhar em uma coisa que você não escolheu, que você não queria, você vai trabalhar só pelo dinheiro porque você precisa, isso é horrível.

Eu não vejo perspectiva de arrumar emprego, não nesse cenário atual, que tão... nesse cenário que os empregadores colocam. Eu não vejo nenhuma perspectiva, mesmo tendo curso, mesmo sabendo informática, eu não vejo perspectiva alguma. Acho que a minha única perspectiva é trabalhar em algum negócio informal, por conta própria, coisa assim.

As questões suscitadas por Luísa revelaram um tom nostálgico e resignado, de quem experimentou um mundo do trabalho constituído de outra forma, por exemplo, tendo até certa facilidade para se deslocar de um emprego para outro durante vários anos, mas que se vê diante de uma série de obstáculos (idade, maternidade, formação, gênero, crise econômica e produtiva etc.) e não encontra espaço para se inserir neste "abominável mundo novo". Assim, dentre as pessoas entrevistadas nesta pesquisa, sua situação é a que mais se aproxima da idéia propalada no senso comum de como o desempregado estaria se sentindo atualmente.

\section{Maria: o sofrimento e a entrada no mundo do trabalho}

Maria tem 23 anos e está cursando o quarto ano do curso de arquitetura. Disse estar muito angustiada com o fato de, em sua idade, não poder trabalhar, pois seus estudos requerem dedicação em tempo integral. Ela acha muito importante ter alguma experiência prática antes de se formar, por acreditar que isso irá ajudá-la a conseguir um emprego no futuro. Maria não considera os "bicos" que faz como experiências de trabalho, sentindo-se em desvantagem em relação aos amigos empregados.

Então, eu pego assim uns servicinhos que são meio bico assim, né, que faz em casa. Eu desenho
algumas plantas de arquitetura no computador, mas é coisa que não é sempre que tem, e
quando tem é pra ontem, assim. É uma pilha de coisa que eu tenho que passar a madrugada
desenhando e tenho que entregar logo... Aí eu, eu... fico me sentindo assim... muito atrasada
porque eu tenho muito amigo e amiga que fazem [nome de uma faculdade], que fazem outras
faculdades que são meio período, e eles conseguem trabalhar e estudar... E aí eles já são
efetivados, ganham relativamente bem, assim, e eu não, assim. Eu fico até preocupada, sabe,
quando eu me formar eu não vou ter tido experiência... Mas também, também tem gente na
[nome da faculdade em que estuda] que, apesar de ser integral, diz que consegue se virar,
assim, diz que consegue um trabalho de noite. Também tem gente que não se importa em
trancar a faculdade, mas... Pra mim me incomoda, assim, não poder trabalhar, eu fico ansiosa,
assim, pra poder trabalhar.

Essa ansiedade que ela disse sentir parece-nos relativa a um medo do desemprego projetado no futuro como uma realidade possível. Já saiu à procura de estágios, porém, quando conseguia a vaga, acabava desistindo. Essa procura pode ser vista como uma maneira que Maria encontrou para lidar com esse medo, uma maneira de "testar" sua empregabilidade. Parece-nos que ela não quer começar a trabalhar agora, mas sim saber se consegue empregar-se ou não, saber se tem as qualidades necessárias ditadas pelo chamado discurso da competência, o qual lista uma série de características e atitudes que o candidato a uma vaga de emprego deve ter e tomar para caracterizar-se como alguém competente para a 
vaga e, portanto, capaz de preenchê-la. Ela teme ser empregada, também, em função de uma experiência ruim de estágio quando fez curso técnico de edificações, no qual se sentiu massacrada e ficou muito decepcionada.

Tanto que eu não corro muito atrás porque eu sei que quem faz lá na [nome da faculdade em que estuda] e quem sabe mexer no computador... Eu não tenho dificuldade de arranjar emprego, eu acho que eu não tenho dificuldade. Então eu não vou muito atrás, porque eu já fui algumas vezes atrás e a pessoa falou: "Então tá, cê começa". Aí, eu parei pra pensar que não valia muito a pena trancar [a matrícula na faculdade]. Então eu já não vou muito procurar porque... Eu sei que eu não tenho dificuldade. Então fica assim: "Ah, então por que você veio fazer a entrevista, então?" (...) Mas é minha curiosidade, para ver se eu consigo, se eu vou... E aí eu não acho que eu tenha dificuldades, assim, de encontrar.

Parece-nos que, articulada a essa questão, surge ainda a angústia que sente frente à iminente inserção no mundo do trabalho. Maria disse que não lida bem com mudanças. Pelo que nos contou, sua vida, especialmente no âmbito familiar, foi marcada por muitas mudanças provocadas pela instabilidade com relação ao emprego. Ela contou como a rotina da casa e da família mudou quando, há dez anos, seu pai ficou desempregado durante um período muito difícil, logo após a morte da mãe de Maria.

E aí tinha... Meu pai não gostava que a gente acordava tarde; acordava cedo, então não podia dormir até mais tarde. E eu tinha que levantar, já tinha que arrumar meu quarto, não sei o quê. Então eu não gostava muito não, assim, e ele ficava... Aí ele ficava lendo uns livros, dando uns telefonemas, às vezes ele saía, tal, sempre meio tenso assim, né... Aí tinha que ir no mercado, tinha que fazer compra, essas coisas e ele ficava sempre de olho no preço de tudo, assim.

Outra mudança deu-se quando seu pai viu-se obrigado a mudar de cidade em função do emprego e ela passou a morar com um parente. Contou também um outro episódio marcante, quando seu pai, visando ocupar um cargo melhor em uma empresa, começou a cursar uma outra faculdade; porém, mudanças na organização da empresa inviabilizaram seus planos. Tais acontecimentos parecem ter despertado questionamentos em relação à representação de emprego: ora visto como algo estabilizador e seguro, ora visto como fonte de insegurança e ansiedade diante da imprevisibilidade do amanhã.

Um outro motivo que leva Maria a procurar emprego é a busca do estímulo que não vem encontrando na faculdade. Para ela, o trabalho seria algo que estimula a vida, nesse sentido, o reconhecimento é de extrema importância e é dele que vem sentindo falta.

Notamos que, se por um lado, ela quer trabalhar logo e conquistar sua independência, sair da faculdade que está desinteressante, por outro, vem o medo de não conseguir emprego e de ter que fazer algo de que não goste e de tudo de novo que isso traz. Uma contradição semelhante reside no fato de que, ao mesmo tempo em que diz sentir-se ansiosa para ter alguma ocupação diária, coloca uma série de condições e restrições ao emprego: não gosta de regras, horários, chefe... Como solução para todos esses conflitos, Maria sonha com um trabalho em situação descontraída, oposta às regras e obrigações próprias dos vínculos empregatícios, e que também garanta estabilidade e segurança.

Tem eu e mais dois amigos que a gente trabalha com esses trabalhos que aparecem de repente. Dai a gente trabalha em casa, todo mundo junto, de madrugada, eles ficam tomando cerveja, desenhando... Que não é nada que... E eu acho muito mais legal do que ter que acordar às oito, ir trabalhar, a gente gosta de trabalhar... Então, se eu pudesse, assim, eu acho muito mais... A questão não é assim, estar empregado ou desempregado, de, de... segurança, tal; a questão é eu saber que eu estou trabalhando, assim, tanto que... tanto que quando eu tô trabalhando eu me sinto melhor, mesmo que eu não tenha prova, que eu tô trabalhando, assim, eu sei que eu tô trabalhando. 
A representação de trabalho mais comum é o emprego, representação que permeia o processo de socialização de vários segmentos sociais. O conflito de Maria, apresentado no parágrafo acima, parece surgir na medida em que ela percebe que sua vontade não corresponde a essa representação comum de que o ideal de trabalho é o emprego. Tal representação acaba se colocando como uma imposição sem sucesso, pois dela Maria não se apropria totalmente, permanecendo o conflito. Além disso, ela se vê angustiada diante do quadro de diminuição das ofertas de emprego. Entretanto, essa mesma situação angustiante parece não só abarcar, mas também possibilitar um sentimento de esperança de Maria em realizar seus sonhos:

Outra também, eu, eu não tenho... É que na verdade é assim, se eu tivesse grana, eu trabalharia com... objetos de decoração, assim, faria uma loja dessa, desse tipo, que precisa de casa, precisa ter máquina, ter não sei o quê... Então, eu acho que se um dia eu não conseguisse emprego, nada, eu já tenho vários desenhos, vários projetinhos, eu ia tentar construir, fazer, desenvolver, assim... sozinha mesmo, não sei, que isso é uma coisa que me entusiasma mais, se eu... passaria a madrugada, o dia inteiro fazendo, mas daí ia depender de ter dinheiro também.

Portanto, no caso de Maria, o sofrimento parece comunicar-se com o desemprego na medida em que este último é sentido como uma forte possibilidade para o futuro. Falamos em futuro pois, no presente, Maria acaba não se dispondo realmente a se empregar quando consegue uma vaga de emprego. Isso nos leva a pensar que Maria está sob pressão do já citado discurso da competência, parecendo-nos que, quando busca por um emprego, seu objetivo é apenas saber se conseguiria a vaga, se encaixa-se no perfil do "empregado perfeito", e não se empregar de fato; e, ao mesmo tempo em que se preocupa com a possibilidade de vir a não conseguir um emprego, Maria parece angustiar-se quando sente que o trabalho que a realizaria profissionalmente e a deixaria feliz não seria nos moldes do emprego, mas sim, o trabalho que realizaria através de um negócio próprio, tendo nesse momento que abrir mão de uma idéia de estabilidade e de segurança ainda contida no vínculo empregatício, idéia que ao mesmo tempo foi e é muitas vezes colocada em xeque na vida de Maria.

\section{Madalena: o descompasso entre a capa e a pessoa}

Madalena tem 30 anos e trabalha como técnica de recursos humanos em uma instituição pública. Começou a trabalhar para conseguir atender as suas "vaidades" e conquistar independência financeira. Já trabalhou como babá, recepcionista, secretária, atendente de telemarketing e auxiliar de recursos humanos. Notamos, ao longo da entrevista, que inicialmente o trabalho representava para Madalena uma maneira de ganhar dinheiro e aos poucos foi se tornando uma possibilidade de conquista de um status que lhe conferisse dignidade. Ela conta que passou por altos e baixos, sempre na busca de um emprego em que sentisse segurança e a possibilidade de crescer e passar "...de um estágio de só obedecer a colocar as... idéias em prática".

Para atingir esse lugar que ela almeja, acredita que é preciso conhecer bem a situação social, o funcionamento do mercado de trabalho e demonstrar, em uma entrevista de seleção, ser aquilo que o selecionador quer, mesmo não sendo. Madalena parece ter desenvolvido a capacidade de ser a entrevistada perfeita, a trabalhadora perfeita dos dias atuais: polivalente, pró-ativa e capaz de suportar as ambigüidades e pressões psicológicas da empresa flexível. Podemos dizer que "vestir essa capa" a despeito do que sente é a estratégia de sobrevivência. É a sua estratégia contra o desemprego. A disparidade entre a "capa" e o que Madalena sente pôde ser percebida durante a entrevista no descompasso entre seu discurso, bastante racional, e sua voz (apenas a voz), sempre em tom de choro contido. 
...mais do que o problema social que a gente vive hoje é a falta de preparo das pessoas que vivem num mesmo país sabendo dessas dificuldades sociais, é não estarem preparados para isso...

...mas o que era percebido é que essas pessoas que estavam assim: tudo, tudo por um emprego, dois meses depois já eram aquelas pessoas que amotinavam, que tinha aquele sentimento meio que grevista, entendeu? [emociona-se] E as empresas têm aversão por estas pessoas, elas preferem aquele pacato cidadão, que tudo está bom. Não tem aumento: "Ah, Maravilha!". Tem que trabalhar, fazer hora extra: "Ah, Maravilha!" E deixam de reivindicar os direitos. E é esse o tipo... é esse o tipo de profissional que o mercado quer hoje, o não excluído.

Então eu tive escalas crescentes e decrescentes e assumi tudo isso como se fosse uma coisa que eu gostaria que acontecesse na minha vida. Pode ser que foi regressão? Não sei, mas essa é a única forma que eu encontrei de subsistência...

O desemprego representa humilhação para Madalena. É o lugar do "não qualificado", o que não tem utilidade; é um não-lugar. Ela sofre mais pela idéia de não poder ter algo do que por não ter de fato. Ela descreve a angústia e o esgotamento das entrevistas na busca pelo emprego; são situações marcadas por humilhação, submissão e alteração dos valores de caráter pela competitividade. Tais situações levariam à baixa auto-estima e à dificuldade de desempenhar aquele papel necessário para conseguir um emprego; dificuldade de vestir a "capa" do entrevistado perfeito, do qualificado, do herói sem rosto que as empresas "flexíveis" buscam.

Nossa! Uma angústia fenomenal, apesar de serem períodos pequenos, eu acho que o período que mais me torturou foi o período em que eu estive aqui em São Paulo mesmo. Que foi... Que tinha o dinheiro regrado pra ir, tinha que saber chegar a lugar e ter um vale transporte pra ir, um pra voltar [emociona-se] e se acontecesse qualquer imprevisto, nossa, eu tava completamente perdida... saber que eu não tenho dinheiro pra comprar um lanche ou saber que não tenho dinheiro pra ajudar nas despesas da casa onde eu estava, que era do meu irmão, todas essas situações realmente afetam psicologicamente. Sem contar que, se você está trabalhando, você tem, consegue manter a sua auto-estima porque você está produzindo alguma coisa; se você perde isso, automaticamente e psicologicamente você já acha que não serve, que você não está no mercado, que você não é qualificado e aí você já vai pra entrevista totalmente negativo... pra desempenhar o seu papel de entrevistado numa entrevista.

É neste âmbito que Madalena vê a importância da psicologia: aquela que irá fortalecer o sujeito para que ele possa "vestir a capa" e conseguir um emprego.

Se todos esses desempregados, mesmo os não qualificados, pudessem ter uma orientação psicológica pra retornar ao mercado de trabalho, eu acredito que pra eles como pessoa e pra eles enquanto trabalhador procurando emprego é assim de suma importância, porque ele vai mais tranqüilo sabendo que ele tem um lugarzinho, mesmo que pequeno, mesmo o gari sabendo que ele pode desempenhar bem a função, que o grande medo é: "será que eu vou conseguir fazer com que eles me arrumem este emprego?". É essa a neurose que todo desempregado tem: "será que eu vou mostrar?" e aí vem desde a questão estética, né, que algumas se armam feito uma árvore de natal e vão toda enfeitada, outras vão com um decote até aqui e outros vão mostrando o que tem de melhor.

Diferenciando-se desses procedimentos que critica, Madalena apresenta sua própria estratégia de sobrevivência: ser o que o mundo do trabalho demanda, a despeito do que sente que é. Tal estratégia parece-nos marcada pela idéia da determinação pessoal como peça fundamental; tudo depende da determinação, do sujeito, ou melhor, da confiança do sujeito que será avaliada pelo entrevistador.

Que nós somos o que acreditamos ser, eu acredito fielmente nisso, eu acredito que posso, eu poderei. Mas se nem eu acho que eu posso, quem vai achar que eu posso fazer? É tudo tão 
complicado e poucas pessoas conseguem se sobressair, enfim, e crescer o padrão de vida, aumentar o padrão de vida, ou comprar, adquirir bens, enfim. Eu ainda não estou nesse estágio. E eu também não sou essa pessoa bem sucedida, eu também tenho todas as minhas fraquezas e todas as minhas neuras.

Primeiro, a falta de qualificação. Hoje fala-se de desempregados, mas os desempregados não têm qualificação alguma para desempenhar função alguma, estes vão continuar sendo desempregados, mas não considero culpa deles ou talvez sim, ou talvez não. Eu também sou de origem humilde e nem por isso eu tapei os olhos e quis me autoflagelar: "Eu sou pobre, eu sou... coitadinha de mim".

Se eu vejo que uma pessoa está sendo massacrada e eu tenho como fazer alguma coisa, eu faço e coloco a minha cara a tapa, coloco e seja o que Deus quiser. Mas eu acredito que ela tenha que fazer a parte dela e não eu levantar uma bandeira e ninguém mais fazer nada, isso é como uma pessoa se queima.

Porém, essa estratégia evidencia um conflito que culmina numa falta de reconhecimento de si mesma que ela traduz como "perda dos valores de caráter". Por um lado, ela critica a necessidade de uma "capa", critica os critérios dos entrevistadores, mas, por outro, adapta-se por não vislumbrar outra solução.

Entrevistadora: É por causa disso que você veio procurar o plantão?

Maria: Oitenta por cento disso. Eu estava totalmente desiludida, porque eu estava perdendo os meus valores de caráter e isso é uma coisa muito ruim.

E: Como assim, valores de caráter?

M: Porque eu estava me tornando uma pessoa tão mesquinha quanto a pessoa que me fazia mal [chefe] e eu comecei a desejar mal a ela assim como ela desejava a mim. E, na verdade, eu não... Ela não tem que mudar a mim nem eu a ela; ela pode ser ela com todas as suas maldades e eu posso me defender.

Então, eu sempre questionei os critérios, como eles podem, não basta uma pessoa ser maravilhosa e pode ter estudado lá na faculdade, fundação "rintintim-rontontom" e ela é estupenda, maravilhosa ou um coitadinho que manca de uma perna, que tem um problema físico e estudou na Universidade de São Paulo, se o entrevistador quiser a sua estética, ele vai ficar com aquela. E isso é muito triste porque você não vale o que você já aprendeu e eu questiono isso.

\section{Marcelo: estigma e sacrifício}

Marcelo tem 33 anos, mora com a mãe e cursa a graduação de uma faculdade pública. Trabalhava em uma agência publicitária como desenhista há oito anos atrás, quando foi despedido em virtude da incorporação de novas tecnologias em programas de computação que reduziram a necessidade de desenhistas por parte das agências. $\mathrm{O}$ motivo de sua participação na pesquisa foi, segundo ele, a vontade de contribuir com seu depoimento para um estudo que enfocasse um tema relevante.

Segundo Marcelo, falar de questões como o sofrimento ligado ao trabalho causa desconforto, o que é evitado pelas pessoas. Levantamos a hipótese de que a possibilidade de falar sobre um assunto marginalizado em muitos ambientes tenha influenciado sua decisão de participar. $O$ entrevistado afirma ser discriminado freqüentemente em função de sua condição de desempregado. Seu discurso denota uma vivência de estigma e de sacrifício: 
O desempregado é sempre um rejeitado, ele fica sempre marginalizado. Tem uma estrutura perversa sim, que condiciona o desempregado. Moralmente ele é um cara acusado de várias coisas. É como se fosse uma doença, uma chaga que ele tem, estampada assim na testa. Então, ele é desempregado. Então, os olhares que se dirigem a ele são sempre os olhares para um rejeitado, para um marginal, para uma pessoa com uma doença incurável, como se pegasse aquilo, entendeu? É uma coisa que todo desempregado sofre isso, de todas as camadas. Enfim, é isso... E eu sofri isso muito assim...

Marcelo associa o trabalho na atualidade com dinheiro e sobrevivência. A isso ele contrapõe um espaço de realização pessoal, uma espécie de zona de atividade desvinculada do trabalho onde seria possível a felicidade. Para poder circular nessa área, entretanto, seria necessário um ganho financeiro. Sendo assim, o trabalho se mostra para ele como responsável indireto da realização pessoal, através de uma dissociação prazer-obrigação. Sua falta necessariamente acarreta estagnação da vida.

Com o desemprego, segundo ele, seus amigos se afastaram ou permaneceram "de um jeito estranho". O constrangimento tornou-se marca desses relacionamentos. Criou-se, assim, uma mescla de abatimento financeiro e moral que atravessou essas relações, que passaram a se estruturar de outra forma. Diante disso, o entrevistado "opta" pela reclusão:

Eu tenho uma grande amiga chamada [nome da amiga]. E ela... A gente sempre sai. Mas, assim, como as minhas condições financeiras não são as melhores, ela sempre acaba tendo que cobrir alguma coisa na despesa que a gente tem, e essa coisa. Isso gera uma situação meio constrangedora porque embora sejamos bastante amigos... e embora na situação dela eu faria a mesma coisa, eu fizesse a mesma coisa... Pra mim fica uma situação constrangedora porque é engraçado, rapaz, você se sente meio impotente, você se sente meio... entendeu? É... como se fosse um peso pra turma, entendeu? Você não se sente livre. Porque, por exemplo, se você está numa situação interessante, você tá trabalhando, você tá tendo uma remuneração razoável mensal, você pode sugerir programas, você pode marcar um churrasco na sua casa, você pode propor programas, você pode... você está num lugar, você pode querer sair pra outro lugar etc. etc. Essa liberdade, assim, você acaba ficando sem liberdade, coisa louca. Sair, então, é uma coisa... Por exemplo, você tem que ficar dando desculpas. Por exemplo, eu queria, mas eu tô sem grana. Eu queria fazer isso, mas eu tô sem grana. Aí começa toda aquela história do outro lado: "não, não tem problema, não tem problema". Você sabe que isso não é problema, "depois você me paga, depois você me paga". E a conta vai aumentando e isso gera uma situação desagradável, pra pessoa, não é. Não é muito agradável você ficar nas costas dos outros. Eu pessoalmente não gosto mesmo e até evito muito sair.

Para Marcelo, o trabalho é um campo opressivo. Ao mesmo tempo, ele é necessário a fim de custear outras atividades que, estas sim, corresponderiam à realização pessoal. Há vislumbres de um trabalho vinculado à satisfação, mas ele não é associado a ganhos financeiros. A falta dele é vivida como estigma, que lhe é imposto, e sacrifício, que lhe cabe.

\section{Ermínio: sustentando seu lugar simbólico}

Ermínio tem 54 anos, é casado e pai de dois filhos já adultos, ambos com graduação no ensino superior. Todos moram juntos. Durante a entrevista, exprime uma imagem de si: "fui um empresário". Sua vida profissional começou aos 14 anos, trabalhando como office-boy. Depois, sucessivamente, trabalhou em uma empresa jornalística da família, em uma empresa bancária e em uma empresa de holding. Posteriormente, tornou-se empresário na construtora de seu sogro, quando essa passou a ser administrada por uma sociedade entre Ermínio e dois parentes, lugar que ocupou por vinte e dois anos. Desfeita a sociedade, passou a ser o único 
proprietário da empresa, que faliu após alguns anos. Atualmente, trabalha, na condição de empregado, como vendedor de fixador de próteses dentárias para drogarias. Em sua jornada, enfrentou o problema do alcoolismo, que foi agravado pela falência. Atualmente, o vício está controlado e, segundo ele, marcou-o significativamente.

Ele destacou o desdobramento da mudança de sua condição de trabalho na relação com seus familiares. Ermínio teceu uma crítica à família, referindo-se à época na qual foi empresário. Contou-nos que, quando administrava a construtora, seus familiares esperavam dele algo acima do que ele considerava como suas possibilidades e que se desdobrou para conseguir satisfazer a tais demandas. E é justamente aí, em relação à família, que Ermínio viu alterações importantes após as mudanças vividas. Se antes a vida familiar parecia pautada por uma relação de trocas materiais (viagens, presentes, festas, carros), esses relacionamentos tornaram-se mais afetivos e, em sua avaliação, a família ficou "mais unida". Atualmente seus dois filhos ajudam a pagar as contas da casa. Ermínio apontou, além dessa, outras mudanças. Uma se deu em sua maneira de ser e se relacionar consigo mesmo:

Existiam muitas barreiras que eu não ultrapassava. Hoje eu sou um cara que... Tô disposto a me tratar de peito aberto, entendeu? Disposto a me despir na frente do analista e falar com ele... Mas isso custou a vida, né? Durante a vida toda sofrendo bastante para poder aprender, essa é a verdade.

Ermínio nos contou como se sente em relação à sua forma de ocupação, que, segundo ele, é de "emprego" e não de "trabalho". A diferença entre emprego e trabalho, para Ermínio, é que o primeiro se referiria estritamente a um vínculo salarial e o segundo seria "...o mais importante que tem para o desenvolvimento do sujeito". Sua representação de emprego parece estar ligada diretamente com um fazer que possibilita a manutenção econômica; por sua vez, o trabalho teria a função de "ocupar" e garantir estabilidade de ordem psicológica às pessoas. Essa espécie de "destrabalho" parece estar associado a um tipo de "seqüestro" de seus papéis sociais (marido, pai e empresário), ou seja, a uma suspensão dos papéis com os quais se definia no social.

Apesar de lhe ser penoso ver-se na condição de "empregado" e não de empresário que "trabalha", Ermínio desabafou drasticamente sobre como uma possível situação de desemprego afetaria seria sua vida:

Eu não gosto do que faço [vendedor]. Eu costumo dizer que eu não nasci para fazer isso, eu nasci programado para ser outro tipo de sujeito, mas eu sou obrigado a fazer.

Eu acho que vocês [da psicologia] são o amparo básico pra o sujeito quando tá no desespero, $e$ o desemprego é um desespero. Eu acho que o desemprego é um grande desespero. Eu não sei o que eu faria hoje se eu perdesse o meu emprego; realmente não posso te dizer. Eu acho que seria o caos total. (grifo nosso)

Ao mesmo tempo, para Ermínio, o desemprego não é um problema social, mas um problema de ordem pessoal, relacionado à postura dos indivíduos em relação às escolhas de trabalho ou emprego, segundo a distinção que ele mesmo faz. Percebemos, assim, como é ambígua a significação que "desemprego" tem para Ermínio:

Eu vejo muita gente querendo ingressar no mercado de emprego por cima, muita gente querendo buscar status logo no primeiro... é aquela brincadeira que a gente ouve: "eu queria muito arranjar um emprego de gerente pra cima", nunca queria arranjar um emprego de peão pra baixo, né. Então eu sou meio descrente dessas teorias [que explicam o desemprego por causas sociais] que se pregam por aí. 
O emprego, mesmo se configurando como o que chamamos de "destrabalho", tem sido o único sustentáculo no seu esforço em manter-se materialmente e evitar, ao máximo, "despencar" para segmentos inferiores do espaço social. O entrevistado afirmou que tem mantido um padrão de vida acima daquele possibilitado por seus ganhos, o que pode corroborar essa idéia de uma constante busca pela manutenção de sua identidade de empresário. Mas, ao mesmo tempo em que parece querer sustentar uma posição sem queda de status, ele assume à sua maneira as mudanças ocorridas.

Eu, durante anos e anos, que a minha situação financeira me permitia, eu fiz pra esse... pros meus dois filhos e pra minha mulher tudo que era possivel e o impossivel, sempre acima das minhas possibilidades.

O que eu ganho dá pra uma família sobreviver, não dá pra manter a minha vida, que apesar de ter baixado a níveis bem... baixo, baixo, ainda continua acima dos parâmetros do que eu tô ganhando, por causa do defeito dos vinte e tantos anos, não é verdade? Então, hoje, eu moro... eu moro de aluguel, mas pago aluguel alto. Eu podia pagar, se eu morasse na periferia, eu poderia morar nas mesmas condições com um aluguel pela metade do preço, tá certo. Eu tenho algumas, alguns... algumas coisas que eu faço, que eu gasto dinheiro e... eu, hum, poderia evitar. Então, na realidade, o seguinte: eu poderia estar sobrevivendo muito melhor hoje, se eu tivesse baixado mais ainda o meu nivel de vida. Só que é muito duro você despencar do nível [de empresário] que eu comecei falar pra você do nível que eu tô hoje, tá certo.

O discurso de Ermínio mostrou-se mais organizado ao discorrer sobre seu passado, quando "trabalhava" - momento em que vivia uma "vida de nababo", que lhe permitia, e à sua família, desfrutar de viagens e confortos materiais diversos -, do que ao comentar sua situação atual. Já quando falou sobre o presente, seu discurso foi fragmentado e confuso. Pareceu-nos que, em alguns momentos da entrevista, tinha por referência a antiga posição, algo que chamamos de "discurso do empresário". Nesses momentos, a fala de Ermínio pareceu tentar resgatar o status perdido. Seu discurso ganhava um tom objetivista no qual as idéias apareciam em uma perspectiva de ganhos e perdas, como um cálculo de utilidade ou uma negociação. Pareceu-nos que se sentir "útil" proporcionava uma certa satisfação, como se sentisse mais à vontade para se relacionar. Por exemplo, justificando sua atitude pelo pressuposto de que "...uma mão lava a outra", ele decidiu colaborar nesta pesquisa, como demonstração de gratidão ao atendimento que recebera no SAP.

A ambigüidade no discurso apareceu também, por exemplo, em relação à posição ocupada frente ao entrevistador, que teve dificuldade para definir uma posição clara de onde Ermínio falava. Essa ambigüidade vivida por ele parece estar articulada à dificuldade de situar-se atualmente em algum papel social; uma hipótese é de que muito embora tenha perdido o capital econômico - o que o forçaria a se deslocar para um outro segmento do espaço social -, há o capital simbólico (Bourdieu, 2003) que vem pressionando-o a se manter no "campo empresarial".

Pudemos perceber que, para ele, essa mobilidade (ou "seqüestro") de papéis sociais tem trazido espaço para reflexão e mudança da qualidade de suas relações humanas. Parecenos que mesmo que Ermínio lute para sustentar seu lugar simbólico, o desalojamento provocado pelas mudanças materiais - e dos lugares sociais que ocupa - a que foi submetido abriu-lhe novas perspectivas de questionamento dos seus modos de ser, com os outros e consigo. 


\section{(Des)fecho}

A diversidade dos discursos atesta a impossibilidade de homogeneização: como num jogo de xadrez, diferentes posições se entrecruzam e se separam em uma intrincada rede de significações que só podem ser compreendidas mediante a confrontação recíproca. Desse embate de pontos de vista, a singularidade se dá não como dado, mas como possibilidade que se atualiza e pede uma apreensão não substancialista e sim relacional. Um olhar que, usando a metáfora de Frayze-Pereira (1995), exige um "olho d'água" que siga a fuga do peixe em seu próprio elemento. Deixamos que esses discursos nos interrogassem, sendo nossas análises não uma resposta, mas um "diálogo com" essas interrogações.

...às vezes com uma pessoa da área, assim de psicologia, ela tem os métodos que levam a gente a conversar, e isso traz alívio porque é uma coisa que tava guardada só pra você, e aquilo tava te machucando, te ressentindo (Luísa).

Pudemos "dialogar com" Marcelo uma experiência de "aplainamento", em que vínculos se esgarçam e se dissolvem. Nesse caso, o desemprego torna-se ausência de lugar ou lugar de acusado: quando percebido, o desempregado não escapa ao crivo moral. "Dialogamos com" Madalena, que, por seu turno, traz a experiência de ser uma migrante em busca de emprego que se mistura com o "caos" da cidade de São Paulo e se angustia com os dilemas da disparidade social.

Estranha armadilha desses discursos, que nos falam e calam em um só movimento. Não pretendemos com esse "(des)fecho" desarmar tais falas e as tornar transparentes a alguma teoria qualquer que as "explique".

Levamos em conta os depoimentos nos quais alguns entrevistados afirmaram sentirem-se impossibilitados de conversar nos mais diferentes ambientes sobre o seu próprio desemprego, real ou potencial. Optamos por puxar alguns fios e, no rastro dos discursos, levantamos três hipóteses.

Uma primeira hipótese: há repressão do discurso sobre desemprego, mas não seria qualquer discurso a ser reprimido. O da mídia, apoiado em números estatísticos, os da economia, da sociologia e mesmo da psicologia encontram-se legitimados, uma vez que remetem a uma cientificidade considerada racional e universal. $O$ que vem sendo freqüentemente tolhido, mesmo nos círculos de amigos e parentes, seria justamente o caráter singular dos discursos dos atores sociais concretos. Dessa forma, o desemprego torna-se, para a pessoa, uma espécie de estigma a ser ocultado devido à falta de espaço em que possa tomar lugar.

Aproximando-nos das considerações de Roudinesco (2000), podemos afirmar que vivemos em uma sociedade "depressiva", pois a expressão emergente do sofrimento contemporâneo é diagnosticada como depressão e remediada como tal. A subjetividade é relegada a um segundo plano, uma vez que a intervenção profilática visa eliminar os sintomas orgânicos e tem caráter funcional. Se considerarmos que vivemos uma época em que êxito e sucesso são os critérios predominantes de reconhecimento social e até mesmo de (des)humanidade, os discursos "desadaptados" terão de ser excluídos, já que existem apenas em oposição àquilo que é, existindo/resistindo portanto, paradoxalmente, como ausência.

...às vezes eu não gosto de ligar pras pessoas que estão no trabalho, que são meus amigos, você fala: "Ah, mas vou ligar, tá ocupada, tô fazendo isso, e eu tô aqui sem fazer nada, né". Você acaba perdendo, né, o contato com as pessoas (Luísa).

Ainda sobre a impossibilidade de se falar sobre o próprio desemprego, uma segunda hipótese: uma denegação da experiência dos desempregados como condição da sociedade 
contemporânea. Para tanto, pensamos sobre o conceito de pacto denegativo ${ }^{12}$ de Kaës (1989), segundo o qual uma formação grupal funda-se na denegação de determinados aspectos seus. Formam-se, assim, zonas de silenciamento e de estranhamento da história, pessoal e social.

Eu não tenho opinião mais. Não tenho opinião nenhuma, sobre alguma coisa, porque pra mim tanto faz (André)..$^{13}$

Uma terceira hipótese: diferentemente de outros papéis socialmente legitimados, o que há de próprio no discurso do desempregado aparece como silêncio. O que quer dizer isso? Considerando que cada diferente papel social instituído possui sua linguagem ${ }^{14}$, que essa linguagem mantém relação com a atuação desse papel e que o desemprego tem como característica o não exercício do trabalhar (o desemprego visto como uma não-função), pudemos construir a hipótese de que não há construção social de uma linguagem própria do desempregado. Isso quer dizer que não há uma linguagem que dê os contornos para esse fenômeno no que ele tem de pessoal, o que o mantém, muitas vezes, no lugar do não-dito. Fica a pergunta: como falar do exercício desse papel na forma de um discurso reconhecido?

O desempregado é sempre um rejeitado, ele fica sempre marginalizado (Marcelo).

Diante dessa pergunta, uma questão se impõe: será o desemprego, atualmente, um lugar social reconhecido? Por um lado, sim, uma vez que a interrogação acerca do fenômeno há muito deixou de ser se há desemprego para se tornar: "qual o índice de desemprego deste mês?". Por outro, não, uma vez que constatamos em algumas entrevistas uma restrição ao discurso dos desempregados em alguns círculos. Nessa perspectiva, o emprego está ligado ao lugar social ocupado pelas pessoas e o desemprego poderia ser tomado como um não-lugar ${ }^{15}$. Mas o desemprego é um não-lugar?

Sem contar que se você está trabalhando, você tem, consegue manter a sua auto-estima porque você está produzindo alguma coisa, se você perde isso automaticamente e psicologicamente você já acha que não serve (Madalena).

Sob a hipótese de que há uma restrição do discurso a partir do lugar do desempregado, algumas questões já se apresentam sem possibilidade de resposta: o que se espera do desempregado? O que essa sua condição demanda? É possível, atualmente, encontrar respostas para essas perguntas (livros de auto-ajuda ou empresas de recolocação profissional, por exemplo), porém, seus formuladores reconhecem o desempregado como consumidor de produtos ${ }^{16}$ num mercado de "saúde social", apontando o desemprego como sociopatia e localizando-o no indivíduo. $\mathrm{O}$ exercício dessas práticas geralmente não prioriza

12 Kaës (1989) comenta o pacto denegativo: “O agrupamento humano não pode se formar senão mantendo zonas de obscuridade profunda... Chamo de pacto denegativo a formação intermediária genérica que, em qualquer vínculo - quer se trate de um casal, de um grupo, de uma família ou instituição -, conduz irremediavelmente ao recalque, à recusa, ou à reprovação, ou então, mantém no irrepresentado e no imperceptível, o que pudesse questionar a formação e manutenção desse vínculo e dos investimentos de que é objeto" (p. 27).

13 André é um dos entrevistados cuja análise não consta deste artigo.

14 Berger e Luckmann (1973) comentam a construção do discurso: "A linguagem da cavalaria tornar-se-á diferente da que é usada pela infantaria... A cavalaria usará também uma linguagem diferente mais do que no sentido instrumental. Um soldado de infantaria encolerizado pragueja fazendo referência à dor nos pés, enquanto o cavaleiro mencionará as costas do cavalo. Em outras palavras, um corpo de imagens e alegorias é construído tendo por base instrumental a linguagem da cavalaria. Esta linguagem específica de uma função é interiorizada in toto pelo indivíduo, à medida que vai se exercitando para o combate montado. Torna-se um cavalariano não somente por adquirir as habilidades exigidas, mas por ser capaz de compreender e usar esta linguagem" (p. 185-6).

15 Aqui, remeteria a uma posição à margem, lugar de não reconhecimento, não legitimação e não interlocução. Pretendemos, assim, realizar um deslizamento do termo cunhado por Marc Auge (2003), na sua obra Não-Lugares: introdução a uma antropologia da supermodernidade. 
uma reflexão crítica, aliena o sujeito de sua experiência concreta e são míopes ou refratárias quanto ao sentido ético e político de sua atuação, sendo muitas vezes apenas um corolário de comportamentos possíveis para aqueles que são definidos por uma falta. O que leva, então, a outra questão: como atuar uma condição cujo caráter central é o não-exercício?

Você não pode... ter uma voz ativa, né... (André).

Em nossa pesquisa, encontramos os mais diversos afetos e significações frente à experiência do desemprego ou à sua iminente possibilidade. Essa diversidade se deu não apenas entre uma e outra entrevista, mas também dentro de uma mesma entrevista. Ficar desempregado pode significar não só uma suspensão da estabilidade econômica, mas também uma exposição de cada um e de todos nós diante de si e da sociedade, colocando certezas em xeque. Entretanto, a ideologia que vem se construindo acerca do fenômeno "espera" ${ }^{17}$ a depressão como reação natural ao desemprego. Sob a égide de tal ideologia, só vem sendo legitimado o aspecto depressivo da experiência. Mas... e os outros aspectos que tão fartamente encontramos?

\section{Referências}

Arendt, H. (1997). Entre o passado e o futuro. São Paulo: Perspectiva.

Auge, M. (2003). Não-lugares: introdução a uma antropologia da supermodernidade. São Paulo: Papirus.

Berger, P. L. \& Luckmann, T. (1973). A sociedade como realidade subjetiva. In A Construção Social da Realidade (pp. 173-241). Petrópolis: Vozes.

Bleger, J. (1985). Temas de psicologia: entrevista e grupos. São Paulo: Martins Fontes.

Bosi. E. (1998). Memória e Sociedade: memória de velhos. São Paulo: Companhia das Letras.

Bourdieu, P. (1996). Espaço social e espaço simbólico. In Razões Práticas: sobre a teoria da ação. Campinas: Papirus.

Bourdieu, P. (2003). Economia das trocas simbólicas. São Paulo: Perspectiva.

Castel, R. (2001). Da indigência à exclusão, a desfiliação: precariedade do trabalho e vulnerabilidade relacional. Saudeloucura, 4, 21-48.

Dieese (2001a). A posição do DIEESE sobre a controvérsia das taxas de desemprego no Brasil. Disponível em: http://www.dieese.org.br. [18 de abril]

Dieese (2002b). Elementos para compreender a controvérsia sobre as taxas de desemprego no Brasil. Disponível em: http://www.dieese.org.br. [18 de abril].

Eisenlohr, M. G. V. (1999). Serviço de Aconselhamento Psicológico do IPUSP: breve histórico de sua criação e mudanças ocorridas na década de 90. In H. T. P. Morato (Org.) Aconselhamento Psicológico: novos desafios. São Paulo: Casa do Psicólogo.

Forrester, V. (1997). O horror econômico. São Paulo: Unesp.

Frayze-Pereira, J. (1995). Olho D'água: arte e loucura em exposição. São Paulo: Escuta.

Gonçalves-Filho, J. M. (s. d.). Psicologia Social I: instrução 1 para o trabalho de campo. [apostila]

16 É incrível que hoje em dia até os desempregados sejam explorados como segmento de mercado consumidor para o qual há uma produção específica. Isso corrobora mais uma vez a idéia de legitimação dessa expressão, só que pela sua conformação no papel de doente ou deficitário.

17 A questão da esperança traz consigo um elemento de ambigüidade, pois se trata de um estado de motivação para operar a realidade ou de um estado de estagnação e passividade em relação à mesma realidade. Essa questão poderia ser objeto de um aprofundamento dos estudos sobre a questão do desemprego e do sofrimento psíquico. 
Hermann, F. (1997). Clínica psicanalítica: a arte da interpretação. São Paulo: Brasiliense.

Instituto Brasileiro de Geografia e Estatística (2002). Pesquisa Mensal de Emprego: notas metodológicas. Disponível em: http://www.ibge.gov.br. [18 de abril]

Jahoda, M. (1987). Empleo y desempleo: un análisis socio-psicológico. Madrid: Morata.

Kaës, R. (1989). Realidade psíquica e sofrimento nas instituições. In A Instituição e as Instituições. São Paulo: Casa do Psicólogo.

Luna, S. V. (2001). Introdução ao Planejamento de Pesquisa. São Paulo: Educ.

Mattoso, J. E. L. (1994). Trabalho sob fogo Cruzado. São Paulo em Perspectiva, 8 (1), 13-21.

Menezes Júnior, A. et al. (1999). O problema do desemprego: como ele é trazido até o Serviço de Aconselhamento Psicológico do Instituto de Psicologia da USP. [Apostila]

Roudinesco, E. (2000). Por que a psicanálise. Rio de Janeiro: Zahar.

Rosenberg, R. L. (1987). Aconselhamento psicológico centrado na pessoa. São Paulo: Pedagógica e Universitária.

Schimidt, M. L. S. (2004). Clínica psicológica, trabalho e desemprego: considerações teóricas. Cadernos de Psicologia Social do Trabalho, 7, 1-10.

Seligmann-Silva, E. (1999). Desemprego: a dimensão psicossocial. In La Psicología al fin del siglo: Conferências magistradas del XVII Congresso Interamericano de Psicología (pp. 337-359). Caracas: Sociedad Interamericana de Psicología.

Endereço para correspondência: juranarede@yahoo.com.br 